DOI: $10.1515 /$ ausfm-2015-0032

\title{
Travel Writing on the Edge: An Intermedial Approach to Travel Books and Travel Blogs
}

\author{
Stefano Calzati \\ University of Leeds (UK) \\ E-mail: fhsc@leeds.ac.uk
}

\begin{abstract}
After discussing the limits and potentialities of the definitions of travel writing proposed by Paul Fussell (1980), Patrick Holland and Graham Huggan (1998) and Jan Borm (2004), the article presents a characterization of travel writing both as a genre with a precise rhetorical status, as well as a praxis of knowledge, which derives from the interplay between travelling and writing. Building on this, a comparison between two Italian travel books and two Italian travel blogs about China is proposed. Specifically, by considering these texts as "intermedial transpositions" (Wolf 2008) that realize the same generic and epistemological matrix (i.e. travel writing), a Multimodal Critical Discourse Analysis (MCDA) is conducted in order to assess: 1) how the book and the blog, as different medial formats, interpret the rhetorical features of the travel writing genre; and 2) to what extent the gnoseological and cross-cultural potentials of travel writing, as a praxis of knowledge, is affected by the process of transposition.
\end{abstract}

Keywords: travel writing, blogs, intermediality, genre, epistemology.

In this paper we make a comparison between two Italian travel books and two Italian travel blogs about China. The two selected books are: La Cina in Vespa (Around China on a Vespa), by Giorgio Bettinelli (2008) and La birra di Shaoshan, (A Beer in Shaoshan), by Sergio Ramazzotti (2002); as for the blogs, those chosen are: Cina: terra di grandi contrasti, (China: Land of Big Contrasts), by blogger Millycat (2012; hosted on turistipercaso.it) and Conoscere Pechino tra dinastie e imperatori, (Getting to Know Beijing between Dynasties and Emperors), by blogger Flavia (2013; hosted on "blogdiviaggi.it"). The aim is to investigate how the landing of travel narratives on different medial formats (i.e. the book and the blog) affects the "rhetorical" and "epistemological" status of these texts (these two terms will be discussed shortly). 


\section{Travel Books and Travel Blogs as "Intermedial Transpositions"}

Travel books and travel blogs are considered here as two "intermedial transpositions" (Wolf 2008) that realize a common generic and epistemological matrix: travel writing. To be sure, "intermedial transposition" is a term whose conceptual validity must be assessed in relation to two other notions: namely, "transmediality" and "remediation." The former, coined by Henry Jenkins (2006, 2), acknowledges "the flow of content through multiple media platforms;" in other words, transmediality accounts for the re-distribution of texts (broadly defined) in various media. The latter, instead, has been introduced by David J. Bolter and Richard Grusin (1999) in order to define how a given message is affected when passing from one medium to another. While Jenkins largely considers transmediality as one consequence of the hybridization among media, and sees the web as the medium that promotes such a convergence the most, Bolter and Grusin focus more on the effects that the process of transposition has on a given text, passing from a rendition of "immediacy," when the re-mediated text is as faithful as possible to the original, to "hypermediacy," when the text is deeply modified, according to the affordances of the new medium. Here, the departing point is slightly different, insofar as it concentrates on the various realizations that a whole genre - travel writing - can take. So, the notion of "intermedial transposition" is best suited as it fosters the idea of different occurrences in different media that refer to a common matrix.

\section{The Problematic Definition of Travel Writing}

Clearly, in order for the comparison to be productive, travel books and blogs have to share a certain degree of similarity. This leads directly into the perilous task of providing a definition of travel writing, since it represents the benchmark against which travel books and travel blogs are compared. Despite the increasing interdisciplinary attention to travel writing within academia (for an overview cf. Hooper and Youngs 2004), the attempt to elaborate a commonly accepted definition of travel writing leaves scholars quite far from agreement. According to Paul Fussell's seminal definition, travel books are "a subspecies of memoirs in which autobiographical narratives arise from the speaker's encounter with distant or unfamiliar data and in which the narrative - unlike that in a novel or romance - claims literal validity by constant reference to actuality" (Fussell 1980, 203). 
Such a definition has been repeatedly criticized as it poses at least two problems. First of all, we attest to the hierarchization of "memoir" and "biography;" a hierarchization which is left, in fact, unexplained. Secondly, Fussell conflates the notion of travel writing as a genre with that of the travel book as a medial format. In this latter respect, Carl Thompson writes that "difficulties arise with any suggestion that we can equate travel writing in its entirety with the form Fussell calls the travel book" (Thompson 2011, 19). As a consequence, the intermedial comparison proposed here is particularly fruitful insofar as the travel writing genre seems refractory to any definition that does not also take into account the medium which conveys the text (and the labels "travel+book," "travel+blog;" "libro di viaggio" and "blog di viaggio" attest to this). As a matter of fact, against a well-established trend within socio-linguistics according to which the medium is not relevant for the definition of the genre (e.g. Yates, Orlikowski and Okamura 1999), it is assumed here that the medium that carries the text not only plays a role in the shaping of the genre, but it is consubstantial to it.

Concerning the formal aspect of travel writing, Patrick Holland and Graham Huggan $(1998,14)$ overcome Fussell's hierarchization between autobiography and memoir by arguing that travel writing is a mix of the two: "like other autobiographies," they write, "travel writing seeks to make retrospective sense of discrete experiences;" however, differently from autobiographies, "travel narratives are less concerned with recuperating, or reinventing, a single self, than with following the trajectory of a series of selves in transit. [...] In this sense, travel writing is more closely affiliated with memoir." On this same issue, Jonathan Raban is much more inclusive when he claims that "as a literary form, travel writing is a notoriously raffish open house where different genres are likely to end up in the same bed. It freely mixes narrative and discursive writing” (Raban 1988, 253-4). Finally, pushing this reasoning to the extreme, the most radical position is undoubtedly that of Jan Borm, according to whom "the point to determine is whether travel writing is really a genre at all. I shall argue here that it is not a genre, but a collective term for a variety of texts both predominantly fictional and non-fictional, whose main theme is travel” (Borm 2004, 13).

The point, in fact, is not so much to broaden or restrict the field that travel writing encompasses, but to look at it from a different perspective. More specifically, the attested difficulty of finding a commonly accepted definition of travel writing can be disentangled by recalling Carolyn Miller's words: "an understanding of genre can help us account for the way we encounter, interpret, react to, and create particular texts" (Miller 1984, 151). Put differently, the notion 
of "genre" can (and should) tell us something about how texts work. From here, it is contended that travel writing is not (only) a genre, but more specifically a rhetorical praxis of knowledge.

\section{The Rhetorical and Epistemological Status of Travel Writing}

The adjective "rhetorical" encompasses, in Miller's spirit, the ensemble of semantic, formal and pragmatic features related to travel writing. "Semantic" is here synonymous with content: in particular, travel accounts have to keep at their core the unfolding of a travel experience. By saying "unfolding," and not merely "the theme of travel" (as suggested by Borm), it is stressed that travel writing must be eminently narrative, as Fussell himself suggests. In this sense, travel guides or other predominantly informative texts that focus on travel, but shape it in a non-narrative way, are not considered proper travel writings.

At the same time, in order to overcome the dualistic position about autobiography and memoir, travel writing is regarded more generally as a subjective narrative; that is, a narrative in which the narrator is part of the story (either as an I, or a we). In this sense, the definition provided elaborates on Gerald Prince's characterization of the narrative as the "recounting of one or more real or fictitious events communicated by one or several narrators (more or less overt) to one or several narratees" (Prince 1987, 58). In fact, the term "subjective stance" refers precisely to the overt manifestation of the narrator to which Prince points. To be sure, such a formal feature, far from being congenital to travel writing, has mainly evolved in modern and contemporary travel accounts. Indeed, as Thompson (2011, 79-81) inversely remarks with respect to $17^{\text {th }}$ - and $18^{\text {th }}$-century English travel writing, "the protocols of epistemological decorum established by the Royal Society influenced not only how [sic] one recorded one's observations and presented them to the public, but also what [sic] one observed and recorded. Abstract or metaphysical speculations were to be kept to a minimum, as were subjective impressions, and personal thoughts and feelings." Hence, the overt subjectivity of travel writing is a formal aspect that has emerged over time, namely in concomitance with the consolidation of travelling as a widespread practice (at least in the West).

One more issue concerning the form of travel writing has to do with the discursive distinction between factual and fictional modes of narration. Holland and Huggan advance a valid argument when they state that any neat separation between these two modes is theoretically preposterous, since all accounts are, to a 
degree, fictitious. As a consequence, they come to define travel writings as "fictions of factual representation" (Holland and Huggan 1998, 10). Although this position is certainly wise, it nonetheless misses properly discussing the relation to truth that travel accounts (pretend) to construct. In this sense, it seems appropriate to suggest, in order to exclude from the realm of travel writing fantastic or sciencefiction texts, that travel accounts, independently from their degree of fictionality, have to be plausible. This means, in other words, that travel writings have to describe experiences that really happened, or are likely to have happened.

The last point that remains to be addressed is the extent to which travel writing can be considered a pragmatic genre. With respect to that, it is useful to recall Casey Blanton's definition of travel writings, as texts "whose main purpose is to introduce us to the other, and that typically they dramatized an engagement between self and world" (Blanton 2002, xi). If we couple this characterization with that by Michel, according to whom "to travel, or at least to travel in a certain way, is to write and to write is to travel" (Butor 2001, 71), then both statements can tell us something specific about travelling and writing: namely, that these acts can be regarded as two specular acts of knowledge. On the one hand, a journey, far from being a mere displacement in space, fuels (and is triggered by) what Pierre Bourdieu defines as the desire of "escaping one's inattentive familiarity" (Bourdieu 1990, 35). Such a desire leads, in turn, to encountering otherness, insofar as "all journeys are, in a way, a confrontation or, more optimistically, a negotiation between self and other" (Thompson 2011, 4). Put differently, travelling kindles an attentive (pre)disposition towards the encounter with (and knowledge of) otherness. On the other hand, writing is an act of unavoidable inscription in the text of the writer's self. More precisely, writing is a "differed" and "deferred" act (Derrida 1976) that reveals the presence of the self to itself, by marking a spatial (on the page) and temporal (in the act of writing) distance from it. It is, then, possible to contend that writing entails a form of mirroring (and representation) of the self onto the page. More generally, we could say that travel writing bears a cross-cultural (towards the other) and gnoseological (towards the self) potential for knowledge. Hence, it emerges more clearly in what terms travel writing is a praxis of knowledge: not only (as a genre) is it historically determined, in that it "changes, evolves, and decays" (Miller 1984, 13); but, as a praxis, it is synchronically shaped by the dynamic interplay between travelling and writing as acts of knowledge. In this respect, the focus of the chosen Italian texts is on China because the cultural "distance" between self and other helps make the cross-cultural and gnoseological potentials more evident. 


\section{Intermediality and Multimodality: a Discursive Approach}

From these premises, the aim of the analysis is two-fold. On the one hand, it assesses how the book and the blog realize the rhetorical features of the travel writing genre; on the other, it investigates how the cross-cultural and gnoseological potentials of the texts, as praxes of knowledge, are affected by the process of transposition. Finally, the analysis seeks to acknowledge the extent to which travel blogs can represent a fruitful source of information for introducing a contemporary and more updated image of China to online readers.

In order to address these points, a Multimodal Critical Discourse Analysis (MCDA) of the selected texts is conducted. MCDA is a methodology that seeks to unveil the opaque relations of power (between self and other; author and reader) as manifested in language and in more broadly semiotic details (Aiello 2012). In particular, the analysis looks at: 1) personal impressions and more factual notations about people and places; 2) the presence/absence of images and what they portray.

\section{La Cina in Vespa}

Giorgio Bettinelli (1955-2008) was a notorious Italian travel writer, whose peculiarity was to travel to the remotest regions on earth riding his Vespa. In $L a$ Cina in Vespa (Around China on a Vespa, 2008) he recounts his journey around the Middle Kingdom, which became his country of residence after having met his Vietnamese partner Ya Pei. Although this book can be rightly defined as a travelogue, it is nonetheless true that Bettinelli pours into it all sorts of reflections, thus steering the narration very much in the direction of the confessional diary, whose diegetic boundaries soon transcend the travel per se. Indeed, the recounting of the travel experience is only one aspect of a broader narration that encompasses, in fact, the author's whole life. For instance, the departure only occurs at page 60, and is anticipated by a series of events (such as the death of Bettinelli's father), whose function is to create the preconditions for the journey: “On Sunday $2^{\text {nd }}$ of November," Bettinelli remembers at the beginning, "his voice [that of his father N/A] is hoarse, almost imperceptible; it already sounds like death. [...] I did not get the chance to meet him alive again. [...] Away from Italy, now! Getting off everything, leaving all behind, running away! Away! Taiwan first, for a couple of months. Then China, with a house on the Mekong River and a journey all around.” (Bettinelli 2008, 19; author's translation.) 
Furthermore, it is quite common for Bettinelli to recollect throughout the book either all his journeys around the world, or the other travelogues he has written, so that La Cina in Vespa comes to represent "only" the last of a long series of achievements as a travel writer: "needless to say, having decided to live in China for the next one or two years, while completing the travelogue about the 144,000 kilometres driven between 1997 and 2001, traversing 90 countries, from Ushuaia to Hobart, the idea that I cannot ride a Vespa in my 'elected country' is much more annoying than a stone in my shoe" (Bettinelli 2008, 39; author's translation). More generally, it is possible to contend that the book is overtly focused on Bettinelli's persona as a traveller and a writer. Hence, it manifests a strong gnoseological potential insofar as through its pages the reader comes to know various aspects of the author's life on and off the road.

On the contrary, the cross-cultural potential is often marginalized, despite the fact that during a great part of the journey Bettinelli is accompanied either by Ya Pei, or by his Chinese lover Manuelle, two locals who could easily negotiate between Bettinelli and the Chinese. The erasure of the other is particularly evident when looking at the images inserted in the middle of the book. There are 16 photos in total and in 12 of them the author is photographed alone, staring at the camera. While disclosing very little of the people met by Bettinelli, these images bear an eminently documentary function, as if the author is willing to tell the reader: "Look where I have been!" In fact, in only two pictures a woman (very likely Ya Pei) appears, but the captions, which simply mention the place or the date - "Kashgar, old town;" "Yunnan, south of China, 2008" - are not helpful in clarifying who she is, thus requiring the reader to collate the text and the images in order to disentangle the dilemma. After all, the egocentric connotation of the experience should not come as a surprise when considering that Bettinelli's goal, rather than delving into the Chinese culture, is precisely "to realize a trip on a Vespa that touches all the 33 geographic areas [of China]" (Bettinelli 2008, 48; author's translation).

\section{La birra di Shaoshan}

La birra di Shaoshan (A Beer in Shaoshan, 2002) is a travelogue written by Italian freelance journalist Sergio Ramazzotti. The book narrates the author's ten-day travel experience to the city of Shaoshan, Mao Zedong's birthplace. The intention of Ramazzotti is to understand something more about China and to introduce the country to Italian readers. The following dialogue between the author and 
Celia, his interpreter, frames well Ramazzotti’s purposes: “Actually, I'm here also to work,' I said. She stared at me in bewilderment. 'What kind of job?' 'I tell stories. At least, I try.' 'For whom?' 'For the people in my country.' 'And do they listen to them?' 'Somebody does. Somebody.' 'What's the difference? Even a tourist tells stories, right?"” (Ramazzotti 2002, 20; author's translation). Leaving aside the contested representation of Ramazzotti as a traveller/tourist, on this occasion the cross-cultural potential of the text is very evident. At the same time, however, the representation of China and the Chinese, being conceived for a Western readership, largely responds to a rigid set of cultural concepts, the effect of which is to re-produce a stereotypical clash between West and East. The following description of Celia made by the author is an emblematic case in point: "A pair of jeans was enough to make you become detestable because it revealed your desire, maybe concealed even to yourself, to be part of that world you condemned with words. I preferred when you wore a long skirt: that length, so silly, so Chinese [sic]" (Ramazzotti 2002, 50-51; author's translation).

More generally, what this and other similar passages do is to re-enact a power gaze that eventually reasserts, in Grzegorz Moroz and Jolanta Sztachelska's (2010, ix) words, "travel writers' (often unconscious) complex involvement and implication in the projects of Orientalism, colonialism, imperialism and postcolonialism." Such a biased representation also emerges in the unbalanced way in which dialogues between Ramazzotti and Celia are reported. Indeed, it often happens that the author's turns are very long in comparison to his guide's replies, as if he is willing to assume a demiurgic position over her and before the eyes of the readers. Here is an example: "[Celia]: 'You have been to Shanghai. You have seen the skyscrapers.' [Ramazzotti]: 'Celia, I slept in the Jin Mao. The hotel begins on the $54^{\text {th }}$ floor, the previous 53 are all empty.' [Celia]: 'The television didn't mention that.' [Ramazzotti]: 'No, but that's the truth. It is an empty crystal tower only good to shout to the world: Guys, look at us, we too are able to build skyscrapers. Why don't you invest money in our country? And it also says to the Chinese: See? We were right. In Tiananmen square, when we shot at your sons, we defended communism, and these are the results.' [Celia]: 'But...' she tried to reply” (Ramazzotti 2002, 170; author's translation).

While the (biased) representation of China and the Chinese imbues the whole book, to be fully suppressed from the text is its gnoseological potential. More precisely, Ramazzotti avoids inserting personal anecdotes or autobiographic information, as if too many details of this kind could weaken the reliability of his reporting. In this respect, the absence of images is notable; an absence which is 
even more striking considering that Ramazzotti is not only a freelance journalist, but also a professional photographer. The point is that, although images can certainly be regarded as documentary proofs about the accomplishment of the journey (as in Bettinelli's case), they can also represent "a real menace to the ontological specificity of fiction" (Baetens 2007, 237). In this sense, images are less subject to the control of the author insofar as "in a single blow, that which is presented to us is so immediate, so non-mediated, that within the shock itself there is a loss of mastery [emphasis added]" (Van Lier 2007, 29). Ramazzotti himself is well-aware of this risk, as he confesses his uneasiness in finding a compromise between photography and fiction: "I do believe that words and images are complementary expressive forms; however, in some circumstances such as in the case of a narrative account - words are by far more striking than images. I like to think that readers imagine together with me the diegetic world I am building” (Ramazzotti, private communication). Hence, by avoiding inserting pictures in the book, Ramazzotti manages to filter all information through his discretion, so that his control over the representation of himself and of China is eventually much stronger.

\section{Cina: terra di grandi contrasti}

Cina: terra di grandi contrasti (China: Land of Big Contrasts, 2012) is an Italian travel blog found on the blog platform turistipercaso.it (tourist by chance) and written by blogger Millycat. Even before reading the blog, the name of the platform frames the blogger's persona and her account within a clear-cut tourist representation. Moreover, the way in which the platform is conceived is also responsible for shaping the style and content of Millycat's blog. Indeed, as Kirsten Uszkalo and Darren Harkness $(2012,18)$ argue, "the infrastructure behind the interface is never directly seen by the blogger, but it drives the interface's development, defines its boundaries, enables a web page form to become a post and that post to be offered to readers." In this respect, the platform of turistipercaso.it unfolds a rigid set of policies of use. For instance, it is not possible for Millycat to add pictures within each post of her blog. On the contrary, images are uploaded separately, together with those of all the other members of the community, a feature that tends to de-personalize each account in favour of a communitarian approach to the writing experience.

Besides, each post of Millycat's blog hosts a variety of advertisements, whose intromission, which depends upon Master Advertisement, the agency 
that manages the platform's marketing strategy, enriches the page with extradiegetic elements [Fig. 1]. As a consequence, Millycat's and all the other blogs on turistipercaso.it get closer to multi-purpose portals than to simple travel accounts. In other words, the blogs acquire a commercial potential to the detriment of their diegetic development.

Concerning Millycat's specific writing, it is possible to remark that she tends to fill the posts with travel recommendations that approach the blog to the style of the guide: "the Forbidden City, or Imperial Palace, also called Winter Palace, is one of the most important buildings of the whole country as it represents a symbol of traditional China and one of the best preserved buildings of the classical age" (post 5; author's translation). This is only one example from the blog which suggests that Millycat is rather inclined to offer information about what she sees by adopting an objective stance. But in so doing, she inevitably erases her own subjectivity from the text, so that its gnoseological potential is marginalized and the blog acquires an eminently documentary function. The erasure of the self emerges most emblematically from Millycat's personal page, in which the blogger simply states her age, without providing other information or uploading any photo of herself. Moreover, the blogger opts for using an alias, the effect of which is double-sided: while further concealing her real identity, it also generates a ludicization of authoriality, which can be intended as a form of softening of the blogger's authority in relation to the informative pretentiousness of the blog.

The objectification of the blog's content has consequences also on the (non) representation of the other. Specifically, since the blog is filled with travel tips (e.g. costs, flights, accommodation, etc.) that are largely to be enjoyed by other tourists, it lacks any in-depth representation of China or the Chinese. Here is another example: "It is necessary to provide [the Chinese Immigration Office] with the whole itinerary of the journey, otherwise no visa is granted; for a couple of legs of the journey I have directly contacted the hostel via email, instead of booking via standard sites such as 'booking.com or Agora'” (post 1; author's translation). What readers derive from Millycat's blog about China is, above all, information related to the practicality of the journey, which, however, does not offer any cross-cultural bridge. In this respect, Millycat seems more concerned with "the fact of knowing, with having, with knowledge as a possession" (Adorno $1991,84)$, rather than with the delivery of a subjective impression of the country. 


\section{Conoscere Pechino tra dinastie e imperatori}

Conoscere Pechino tra dinastie e imperatori (Getting to Know Beijing between Dynasties and Emperors, 2013) is the title of the first post dedicated to China by Italian blogger Flavia and published on the platform blogdiviaggi.com (travel blogs). The blogger has written a total of five posts on China and, according to the date of the first and last post, she has spent roughly one and a half months in the Middle Kingdom, from the $21^{\text {st }}$ of September to the $5^{\text {th }}$ of November 2013. Again, it is possible to remark that the policies of use of the platform play a key role in dictating how the travel blog can be written and read. Blog di viaggi stresses the individuality of each blogger, urging them to provide a photo of themselves and a biographical note on their profile page: "the beauty of this platform is that it is not a classical site or a travel guide," is stated on the About page, "but it is OUR blog. [...] It is made by travellers for travellers" (author's translation). To support this, the platform offers two complementary reading paths: on the one hand, on the homepage it is possible to browse a world map and read all the posts about any given country. On the other hand, we find on the About page the profiles of all the bloggers and a link to their travel experiences. Therefore, the platform puts an equal emphasis on the gnoseological and crosscultural potentials of the travel blogs. This, however, holds true only insofar as we remain at the level of the platform as a whole. Indeed, once we delve into reading the blogs, the situation changes. Similarly to Millycat, Flavia tends to provide tourist information very much in the spirit of those portals from which the platform pretends to distance itself: "The capital is home to 20 million people and 5 million cars," it is read in the post dedicated to Beijing, "our first visit is to Tiananmen square, which, with its 44 hectares, is the largest in the world. In the middle, there is a war memorial and the flag of the CPR" (post 1; author's translation). Again, the blog is largely composed of a series of objective notations, the consequences of which are: 1) to conceal the subjective position of the blogger with respect to the experience; 2) to rarefy the narration; 3) to offer a matter-of-fact description of the country and the people. In this case, however, it is visible that the posts unfold at best their purely documentary function. Indeed, almost all the images uploaded in the blog show touristic landmarks, and on the rare occasions on which they portray people, these are, so to speak, massified, that is, represented indistinctively as a whole [Fig. 2]. Hence, not only is Flavia's account conceived from the outset for a restricted class of readers (i.e. tourists or other travel bloggers, as the platform suggests), 
but her whole journey and the account derived from it turn out to be very similar to Millycat's.

Finally, in Flavia's blog the objectification of the experience is also evident in the few comments that accompany some of the posts, as the following exchange between her and blogger Eletrotter suggests: "[Eletrotter]: 'Wonderful temples! Maybe one day I'll go to China too.' [Flavia]: 'You have to! If you decide to go, I'll be happy to provide you with tips, so that you can enjoy the best places and avoid the most commercial ones." (Comments to post 3; author's translation.) These comments kindle two reflections: on the one hand, the travel blog largely functions as a carrier of tourist information, keeping its enjoyment self-enclosed within the travel bloggers' community; on the other hand, it responds primarily to Flavia's willingness to testify her journey, without, however, her being concerned with providing a well-rounded representation of the experience. In this respect, both travel blogs confirm the findings about the practice of blogging being a singleauthored activity with a highly self-referential connotation (Papacharissi 2004).

\section{Conclusion}

The analysis showed that travel books and travel blogs, considered as two intermedial transpositions of the travel writing genre, realize its rhetorical and epistemological features very differently. More specifically, the two travelogues La Cina in Vespa and La Birra di Shaoshan present the readers with the unfolding of a proper narrative, which depends upon the "I" of the travel writer. However, while in Bettinelli's book the narration takes the form of a lifediary, thus strengthening the gnoseological potential of travel writing (i.e. the self-representation of the author), Ramazzotti's work is overtly conceived as a reportage, so that the cross-cultural potential of the genre is stressed (i.e. the representation of China and the Chinese).

Travel blogs, on the contrary, are largely constituted by objective notations and/or by tourist advice which bring these texts close to the travel guide. This tendency is so prominent in both Cina: terra di grandi contrasti and Conoscere Pechino tra dinastie e imperatori that the narrative almost disappears in favour of a mere juxtaposition of documentary information. As a consequence, the two blogs manifest an erasure of both the subjectivity of the travel blogger, as well as of China and Chinese people. In fact, such an erasure occurs either verbally (i.e. self-referentiality of the comments), or visually (i.e. pictures that privilege places over people). At the same time, if travel blogs appear much more documentary- 
like than travel books, it is also due to the infrastructure of the blog platforms, whose policies of use constrain what bloggers and readers can do much more radically than publishers do in books. Further research would require extending the analysis to travel blogs that are not hosted on platforms, but are independently managed by the bloggers.

On a general level, the two travel blogs appear as rhetorically more homogeneous than the travel books. In this respect, it is possible to suggest that (these) travel blogs cannot effectively represent an alternative to travel books, nor constitute an effective source of information for knowing China and the Chinese; rather, they are texts which reinforce the representation of the country as a tourist destination.

\section{References}

Adorno, Theodor. 1991. The Culture Industry: Selected Essays on Mass Culture. London: Routledge.

Aiello, Giorgia. 2012. All Tögethé® Now: The Recontextualization of Branding and the Stylization of Diversity in EU Public Communication. Social Semiotics vol. 22 no. 4: 459-486.

Baetens, Jan. 2007. Image and Narrative. In Routledge Encyclopedia of Narrative Theory, eds. David Herman, Manfred Jahn and Marie-Laure Ryan, 236-7. London: Routledge.

Bettinelli, Giorgio. 2008. La Cina in Vespa. [Around China on a Vespa]. Milano: Feltrinelli.

Blanton, Casey. 2002. Travel Writing: The Self and the World. London: Routledge. Bolter, David J. and Richard Grusin. 1999. Remediation: Understanding New Media. Cambridge, Massachusetts: MIT Press.

Borm, Jan. 2004. Defining Travel: On the Travel Book, Travel Writing and Terminology. In Perspectives on Travel Writing, eds. Glenn Hooper and Tim Youngs, 13-26. Farnham: Ashgate Publishing Ltd.

Bourdieu, Pierre. 1990. Photography: a Middlebrow Art. London: Polity Press. Butor, Michel. 2001 Travel and Writing. In Defining Travel: Diverse Visions, ed.

Susan L. Roberson, 65-89. Mississippi: University Press of Mississippi.

Derrida, Jacques. 1976. Of Grammatology. Baltimore: Johns Hopkins University Press.

Flavia. 2013. Conoscere Pechino tra dinastie e imperatori. [Getting to Know Beijing between Dynasties and Emperors]. http://blogdiviaggi.com/blog/2013/09/21/ viaggio-a-pechino-cosa-vedere. Last accessed 03. 05. 2015. 
Fussell, Paul. 1980. Abroad: British Literary Travelling between the Wars. Oxford: Oxford University Press.

Genette, Gérard. 1997. Paratexts: Thresholds of Interpretation. Cambridge: Cambridge University Press.

Holland, Patrick and Graham Huggan. 1998. Tourists with Typewriters: Critical Reflections on Contemporary Travel Writing. Ann Arbor: University of Michigan Press.

Hooper, Glenn and Tim Youngs. 2004. Perspectives on Travel Writing. Farnham: Ashgate Publishing Ltd.

Jenkins, Henry. 2006. Convergence Culture: Where Old and New Media Collide. New York: New York University Press.

Miller, Carolyn. 1984. Genre as Social Action. Quarterly Journal of Speech vol. 70: 151-177.

Millycat. 2012. Cina: terra di grandi contrasti. [China: Land of Big Contrasts]. http://blogdiviaggi.com/blog/2013/09/21/viaggio-a-pechino-cosa-vedere/. Last accessed 05. 05. 2015.

Moroz, Grzegorz and Jolanta Sztachelska, eds. 2010. Metamorphoses of Travel Writing: Across Theories, Genres, Centuries and Literary Traditions. Newcastle: Cambridge Scholars Publishing.

Papacharissi, Zizi. 2004. The Blogger Revolution? Audiences as Media Producers. Paper presented at the Annual Conference of the International Communication Association. New Orleans.

Prince, Gerald. 1987. The Dictionary of Narratology. Lincoln: University of Nebraska Press.

Raban, Jonathan. 1988. For Love \& Money: Writing-Reading-Travelling 19681987. London: Picador.

Ramazzotti, Sergio. 2002. La birra di Shaoshan. [A Beer in Shaoshan]. Milano: Feltrinelli.

Thompson, Carl. 2011. Travel Writing: The New Critical Idiom. London: Routledge. Uszkalo, Kirsten and Darren Harkness. 2012. Consider the Source: Critical Considerations of the New Medium of Social Media. In From Text to Txting: New Media in the Classroom, eds. Paul Bubra and Clint Burnham, 15-42. Bloomington: Indiana University Press.

Van Lier, Henri. 2007. Philosophy of Photography. Leuven: Leuven University Press. 
Wolf, Werner. 2008. The Relevance of "Mediality" and "Intermediality" to Academic Studies of English Literature. In Mediality/Intermediality, eds. Martin Heusser, Andreas Fischer and Andreas H. Jucker, 15-43. Göttingen: Narr.

Yates, JoAnne, Wanda Orlikowski and Kazuko Okamura. 1999. Explicit and Implicit Structuring of Genres in Electronic Communication: Reinforcement and Change of Social Interaction. Organization Science vol. 10 no. 1: 83-117.

\section{List of Figures}

Figure 1. A screenshot of Millycat's blog (http://turistipercaso.it/cina/68394/ cina-terra-di-grandi-contrasti.html, last accessed 05. 05. 2015) which attests to the intrusion of extra-diegetic elements in the page.

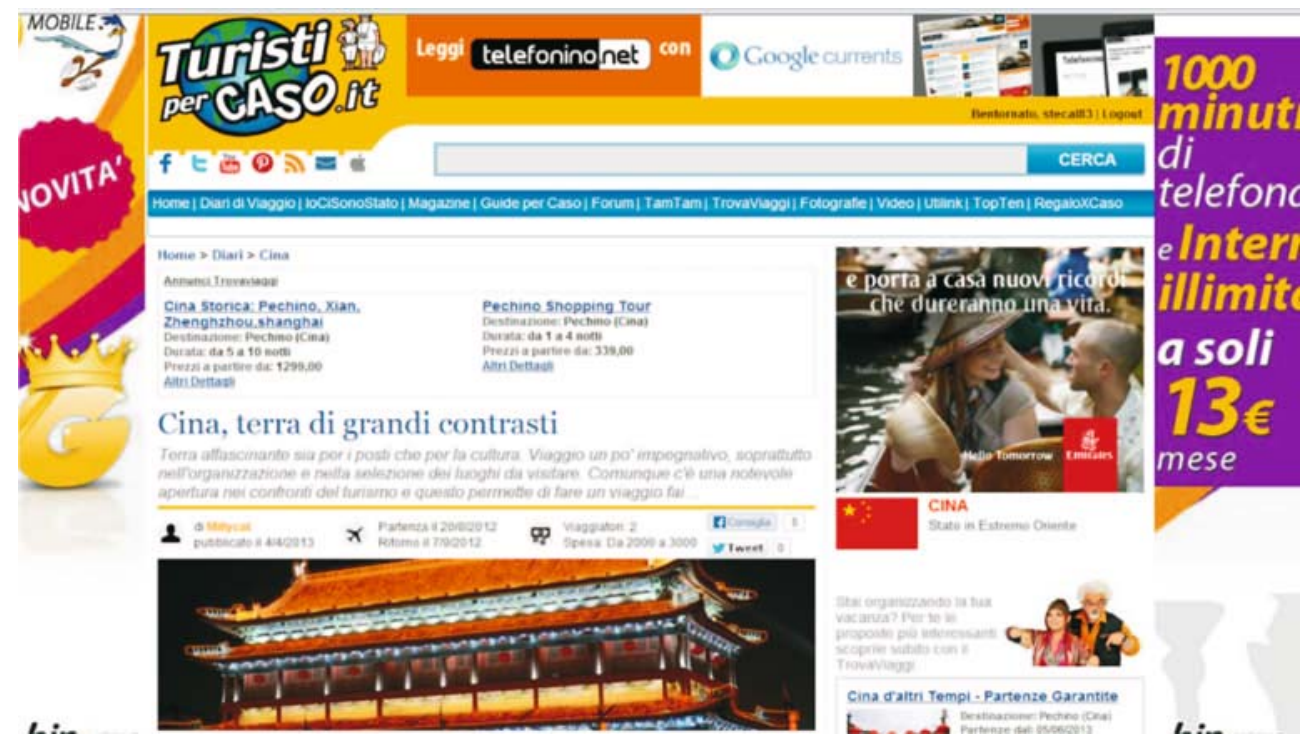


Figure 2. Part of Flavia's blog on China (http://blogdiviaggi.com/ blog/2013/09/21/viaggio-a-pechino-cosa-vedere/, last accessed 05. 05. 2015). The images all represent tourist landmarks; Chinese people are massified.



La Città Proibita è definita tale in quanto risultava la sede politica dell'imperatore e dei suoi prescelti, che peró a sera dovevano lasciare tutti i palazzi e le residenze. Le uniche alle quali era consentito rimanere erano le 3.000 concubine tra le quali l'imperatore ogni sera doveva effettuare una scelta per trascorrere la notte. Dopo una selezione per età, ne venivano scelte 7 alle quali erano destinate differenti stanze, arredate e posizionate in modo diverso a seconda di quelle che erano. piủ o meno, preferite dall'imperatore. All'ingresso della città esiste il Palazzo della Longevità, e a seguire quello dell'Armonia, due strutture all'interno delle quali è possibile ammirare il trono dell'imperatore posto al centro e vari trespoli con dei vasi di bronzo. 